\title{
Cortisol Stress Reactivity to the Trier Social Stress Test in Obese Adults
}

\author{
Benedict Herhaus Katja Petrowski \\ Medical Psychology and Medical Sociology, Clinic and Policlinic for Psychosomatic Medicine \\ and Psychotherapy, University Medicine Mainz, Mainz, Germany
}

\section{Keywords}

Obesity · Hypothalamic-pituitary-adrenocortical (HPA) axis · Cortisol · Trier Social Stress Test (TSST)

\begin{abstract}
Objective: Approximately 600 million adults worldwide suffer from obesity. In addition to individual's eating behavior and lack of physical activity in the development of obesity and overweight, psychosocial stress as well as hormonal stress reactivity must also be considered as important contributing factors. In the current study we compared the cortisol stress response pathway in a psychosocial stress induction (Trier Social Stress Test; TSST) with obese individuals and normal-weight controls. Method: 32 obese individuals (17 females; mean age $=33.94$ years, $\mathrm{SD}=11.31$ years) and 32 normal-weight controls ( 17 females; mean age $=29.09$ years, SD = 10.46 years) underwent the TSST. The salivary cortisol responses and three appraisal questionnaires (Primary Appraisal Secondary Appraisal, Visual Analogue Scale, Trier Inventory for Chronic Stress) were measured. Results: After stress induction, there was a significant main group difference between the obese individuals and the normal-weight controls for cortisol, with lower baseline and post-stress cortisol levels in the obese individuals. Nevertheless, the obese individuals as well as the normal-weight controls showed no significant difference in the self-reported assessment of the stress condition but some significant differences in the cognitive appraisal of the TSST. Conclusion: In conclusion, the induction of psychosocial stress showed differences in the cortisol patterns between the obese individuals and the normal-weight controls. Furthermore, the present data suggest that obesity leads to lower cortisol activity, which may indicate alterations in the Hypothalamic-pituitary-adrencortical (HPA) axis.


Herhaus and Petrowski: Cortisol Stress Reactivity to the Trier Social Stress Test in Obese Adults

\section{Introduction}

Between 1980 and 2014, the adiposity rate doubled worldwide, which means that more than 600 million adults are now obese [1]. According to a recent report by the National Center for Health Statistics, the United States had an obesity prevalence of $36 \%$ among adults between 2011 and 2014 [2]. A BMI above $30 \mathrm{~kg} / \mathrm{m}^{2}$ as a marker for obesity is directly related to diseases such as diabetes, cardiovascular disease, and sleep apnea as well as to a generally higher morbidity [3]. The weight gain, an increased BMI, and psychosocial chronic stress [4-6] might be related to the subsequent harmful adaption of the neuroendocrine systems [7]. Therefore, the functioning of the hypothalamic-pituitary-adrenocortical (HPA) axis under stress in obesity is of great importance for a better understanding of obesity.

A possible reason for a change in the HPA axis in obesity is the increase in the percentage of fat [8]. Hereby, a general correlation between the BMI and cortisol can be observed [9]. A systematic review of Incollingo Rodriguez et al. [10] demonstrated that obese individuals show a greater stress-related cortisol response to laboratory acute challenges. However, the five included studies had methodological differences and limitations [9, 11-14]. Due to the lack of a control group and gender matching and only one study with exclusively male participants [9], the results of the systematic review only allows conclusions on obese women. Furthermore, the cortisol responses are not comparable between the used physiological, psychological and pharmacological acute stressors. It must be considered that the activation of the HPA axis varied widely across different types of acute stressors $[14,15]$.

Concerning the meta-analysis of Dickerson and Kemeny [16], the Trier Social Stress Test (TSST) is considered as an internationally established protocol with a reliable cortisol response to the psychosocial acute stress. Focusing on studies using the TSST in obese individuals, the results are inconsistent [17-21]. These differences might be explained by the fat distribution phenotypes measured by waist-to-hip ratio (WHR). Hereby, a greater stressinduced cortisol reactivity can be observed in abdominal obesity compared to generalized obesity $[11,20]$.

Concerning people with obesity classified by BMI, there are studies which demonstrated a greater cortisol response to the TSST in obese individuals $[17,21]$, but others found no main group effect [18-20]. Thereby, it must be considered that in these studies different ranges of obesity (Class I to III) and age (18-70 years) were included as well as only one study investigated the effect of gender on the cortisol reactivity in obese individuals [19].

Therefore, the current aim was to study the cortisol stress response pathway in a comparison of obese adults and normal-weight controls under the standardized stress protocol of the TSST by controlling gender. Thereby, groups were clearly separated according to ICD-10 in normal-weight (BMI $\leq 25 \mathrm{~kg} / \mathrm{m}^{2}$ ) and obese individuals (BMI $\geq 30 \mathrm{~kg} / \mathrm{m}^{2}$ ) with matched gender and matched age. We hypothesized that obese individuals would show a greater increase in hormonal parameters after psychosocial stress induction than normalweight controls.

\section{Material and Methods}

Study Participants

The participants for the study were recruited through newspaper advertisements, online tendering, and notice boards at different universities. The screening to examine inclusion criteria and medical history was conducted by a prior telephone interview based on the entire procedure of the Structured Clinical Interview (SCID; [22]) for the Diagnostic and Statistical Manual of Mental Disorders (DSM-IV; [23]). The participants of the experimental group were obese according to ICD-10 (BMI $>30 \mathrm{~kg} / \mathrm{m}^{2}$ ) and between 18 and 65 years of age. In addition, a control group was established, which was matched regarding age and gender to the indi- 
Herhaus and Petrowski: Cortisol Stress Reactivity to the Trier Social Stress Test in Obese Adults

Table 1. Characteristics of the participants concerning matching criteria

\begin{tabular}{|c|c|c|c|c|}
\hline & $\begin{array}{l}\text { Obese } \\
\text { individuals }\end{array}$ & $\begin{array}{l}\text { Normal-weight } \\
\text { controls }\end{array}$ & $t / x^{2} / Z$ & $p$ \\
\hline Total, $n$ & 32 & 32 & & \\
\hline Female, $n(\%)$ & $17(53.1)$ & $17(53.1)$ & & \\
\hline Age, years, M (SD) & $33.94(11.31)$ & $29.09(10.46)$ & -1.779 & $0.080^{\mathrm{a})}$ \\
\hline $\mathrm{BMI}, \mathrm{kg} / \mathrm{m}^{2}, \mathrm{M}(\mathrm{SD})$ & $32.36(2.03)$ & $22.10(2.00)$ & -10.264 & $<0.001^{* * * a)}$ \\
\hline WHR, M (SD) & $0.95(0.12)$ & & & \\
\hline Smokers, $n(\%)$ & $0(0.0)$ & $6(18.8)$ & 6.621 & $0.010^{\mathrm{b})}$ \\
\hline Cigarettes/day (of smokers), M (SD) & 0 & $4.87(4.28)$ & & \\
\hline Contraceptives, $n$ (\% of females) & $3(17.7)$ & $8(47.1)$ & 3.360 & $0.067^{\mathrm{b})}$ \\
\hline Medication intake, $n(\%)$ & $0(0.0)$ & $0(0.0)$ & 0.000 & $1.000^{\mathrm{b})}$ \\
\hline $\begin{array}{l}\text { Regular sports activity per week in hh:mm, } \\
\text { M (SD) }\end{array}$ & $5: 01(3: 33)$ & $4: 27(2: 20)$ & -0.620 & $0.539^{a)}$ \\
\hline $\begin{array}{l}\text { Healthy well-being ( } 0 \text { : not at all, } 4 \text { : totally), } \\
\text { median }(25-75 \% \text { percentile })\end{array}$ & $4.00(3-4)$ & $3.50(3-4)$ & -0.592 & $0.554^{\mathrm{c})}$ \\
\hline TICS SCSS, M (SD) & $17.13(8.52)^{\mathrm{a})}$ & $13.56(6.98)^{\mathrm{a})}$ & -1.837 & $0.071^{\mathrm{a})}$ \\
\hline
\end{tabular}

BMI, body mass index; M, mean; SD, standard deviation; TICS, Trier Inventory of Chronic Stress; SCSS, Subscale of Chronic

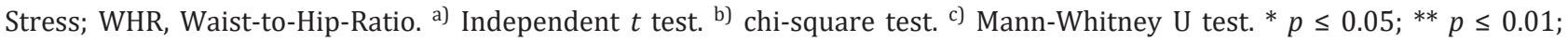
$* * * \mathrm{p} \leq 0.001$.

viduals of the experimental group. Both groups did not differ in age, gender, and use of oral contraceptives (all $p>0.05$ ). Participants with any acute and/or chronic medical illness, any mental disorders, any medication or substance intake, any allergies, and stressful life events in the past 6 months were excluded. Table 1 describes the characteristics of the two groups, which each consisted of $n=32$ individuals. All participants received an allowance of EUR 50.00 after successful participation. All study participants gave written informed consent. The study protocol was approved by the local Ethics Committee of the Medical Faculty of the Technical University of Dresden, Germany (No\#EK26012015).

\section{Procedures}

All study participants were tested on a weekday between 2.00 and 4.30 p.m., thus standardizing the measurements with respect to the circadian rhythm of the cortisol. Considering the influence of the menstrual cycle, the female participants completed the stress test in the luteal phase. In addition, a health questionnaire was completed on the test day to control influencing factors such as sleep duration ("How many hours did you sleep last night?"), regular sport activity ("How many hours do you practice sports regularly during the week?"), alcohol consumption ("How much alcohol did you drink yesterday/today?"), and assessment of healthy well-being ("Are you feeling healthy and well right now?" Scale from 0 "not at all" to 4 "totally"). The study protocol took approximately $90 \mathrm{~min}$ and included three parts: a pre-stress, a stress, and a post-stress phase. A total of 9 saliva samples were collected over the entire duration of the test. Figure 1 shows a detailed overview of the measuring points of the cortisol samples, completion of the questionnaires, and the duration of the three testing phases.

The preparation phase, taking 20 or rather $30 \mathrm{~min}$, began with a stationary period during which questionnaires were filled out. Afterwards, four limb electrodes were placed for the recording of the monitoring system SmartVital (Fraunhofer Fraunhofer-Institut für Photonische Mikrosysteme, Dresden, Germany), and the holter recorder was attached to a belt. $5 \mathrm{~min}$ before the start of the stress test, the participants performed the 3-min respiratory sinus arrhythmia test ( 6 breaths $/ \mathrm{min}$ ). Saliva samples were collected $15 \mathrm{~min}$ and $1 \mathrm{~min}$ before the TSST.

In the 15-min stress phase, the social stress test was carried out, which consisted of three 5-min blocks of preparation, interview, and calculation task. At the end of the preparation period, a saliva sample was taken as well as directly after the TSST. In order to assess the subjective stress perception, the Primary Appraisal Secondary Appraisal (PASA) was performed at the beginning of the TSST and the visual analogue scale (VAS) immediately after the psychosocial stress induction. 
Herhaus and Petrowski: Cortisol Stress Reactivity to the Trier Social Stress Test in

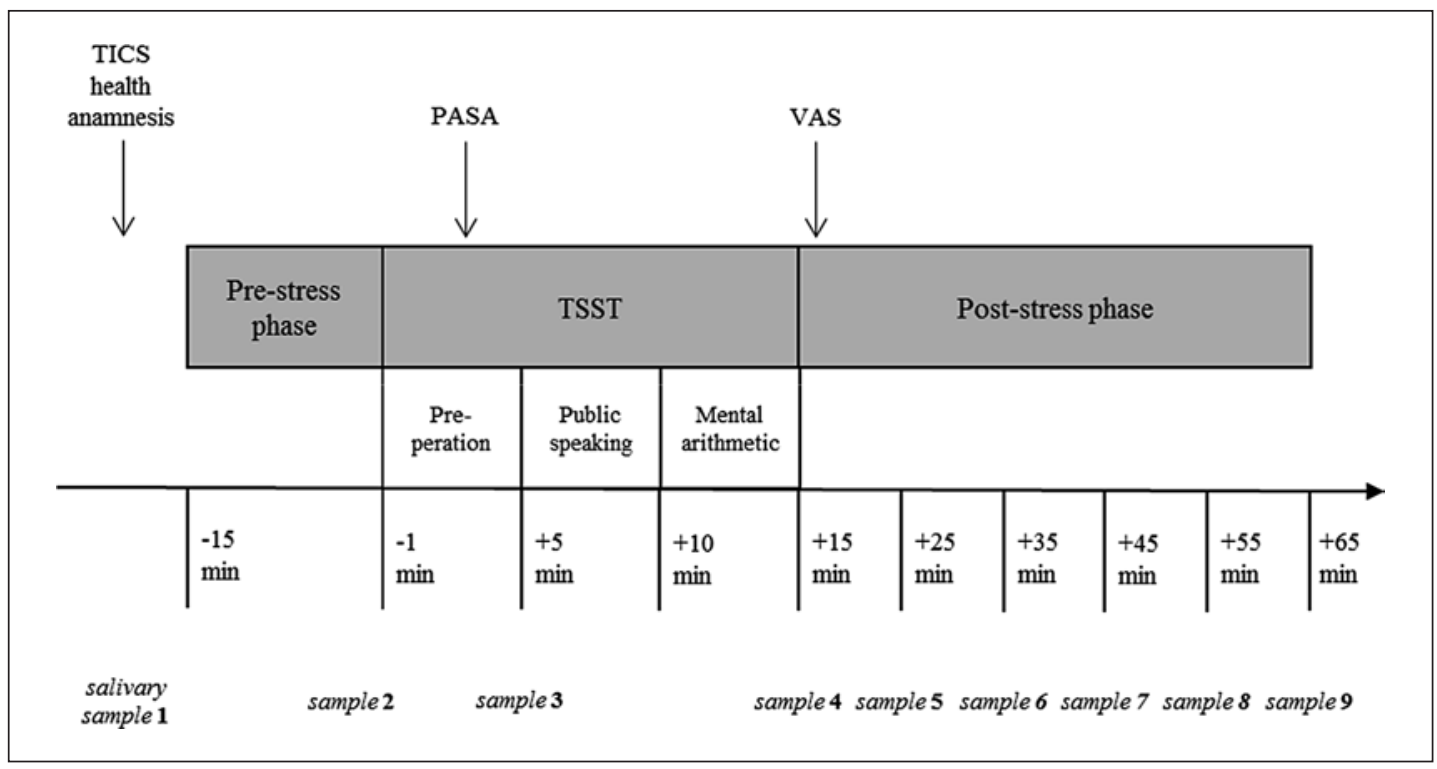

Fig. 1. Measuring points of the salivary samples and questionnaires during three testing phases. PASA, Primary Appraisal Secondary Appraisal; TICS, Trier Inventory for Chronic Stress; TSST, Trier Social Stress Test; VAS, Visual Analogue Scale.

In the post-stress phase, 5 additional saliva samples were collected at a time interval of $10 \mathrm{~min}$, and the remaining questionnaires were completed. To counteract undue arousal, light reading was recommended.

\section{Cortisol Samples and Analysis}

For the specification of cortisol concentrations, saliva samples were collected by moistening a cotton roll in the mouth for $1 \mathrm{~min}$ and then placing it into a salivette ${ }^{\circledR}$ (Sarstedt, Nümbrecht, Germany). After testing, the salivettes had to be protected from heat and direct sunlight and were refrigerated at $2-8{ }^{\circ} \mathrm{C}$. Before the laboratory analysis, the saliva was isolated from the cotton roll by centrifugation. Subsequently, the salivary cortisol concentrations were measured using the luminescence immunoassay (LIA) test method which proved to be robust and valid with an intra- and inter-assay coefficient of variation below $9.0 \%$ [24].

\section{Psychological Stress Protocol}

The TSST which combines uncontrollability, social evaluation, and arithmetic tasks was selected as the stress condition and was carried out according to the published process protocol by Kirschbaum et al. [25]. It is an internationally established endogenous procedure for an acute psychosocial stress response and has so far been applied to more than 4,000 individuals worldwide $[16,26]$. In order to evaluate the subjective perception of stress as well as the cognitive evaluation, the questionnaires PASA and VAS were collected during and after the 15-min stress test.

\section{Psychological Assessments}

Perceived chronic stress was measured by the Trier Inventory for Chronic Stress (TICS) constructed by Schulzet al. [27] which, based on 57 items (five-point rating scale), retroactively evaluates nine interrelated factors as well as an additional screening subscale (SCSS) of psychosocial chronic stress during the previous 3 months. In the current sample, the internal consistency exhibited good homogeneity values of Cronbach's $\alpha$ between 0.84 and 0.88 for the nine scales and 0.90 for the screening subscale. The PASA [28] was used to assess the acute stress condition and evaluates the four cognitive appraisal processes "threat", "challenge", "self-concept of own abilities", and "control expectancy" with a six-point rating scale. Based on the four primary scales, the two secondary scales "primary appraisal" ((threat + challenge) / 2) and "secondary appraisal" ((self-concept of own abilities + control expectancy) / 2) as well as the tertiary scale "stress index" (primary appraisal - secondary appraisal) is calculated. The reliabilities (Cronbach's $\alpha$-coefficient) in the current sample for the four primary scales (between 0.61 and 0.84 ), for the two secondary scales (primary 
Herhaus and Petrowski: Cortisol Stress Reactivity to the Trier Social Stress Test in Obese Adults

appraisal 0.78 ; secondary appraisal 0.78 ) and for the tertiary scale $(0.71)$ demonstrated reasonable homogeneity. The self-reported stress perception after the stress induction was evidenced by the VAS which has proved to be a valid measuring instrument compared to other questionnaires [29].

\section{Statistical Analysis}

In view of a statistically responsible sample, the optimum statistical sample size was calculated with the $G^{*}$ power program (version: 3.1.9.2.). For the analysis of the cortisol output of obese adults and normalweight controls under a stress condition, two-way ANOVA for repeated measures was performed. The assumption of sphericity was controlled by Mauchly's test. Whenever necessary, the ANOVA results were corrected by Greenhouse-Geisser. Based on a medium effect size of Cohen's $f=0.30$, two groups (normal weight vs. obese), $n=8$ repetitions, a significant level of $p=0.05$, and power of $80 \%(1-\beta=0.80)$, a total sample size of $n=12$ for within-subjects factor and $n=50$ for between-subjects factor was needed.

First, differences between the obese group and the normal-weight control group in sociodemographic and influencing variables were examined using the independent t-test, Mann-Whitney U test, and chi-square test.

Second, the effects of the TSST in the two groups over eight measurement points on the HPA axis were analyzed by the two-factorial ANCOVA for repeated measures with the between-factor group and withinfactor time. Oral contraceptive use, smoking status, and age were included as covariates in the repeated measures model to control potential influencing factors of the cortisol. The cortisol values were subjected to natural log transformations due to not normally distributed data. Additionally, the area under the curve (AUC) with respect to ground $\left(\mathrm{AUC}_{\mathrm{G}}\right)$ and increase $\left(\mathrm{AUC}_{\mathrm{I}}\right)$ as well as the delta between peak and baseline $(\Delta$ peak-base) were calculated [30]. The $t$ test for independent samples was performed to evaluate the difference between the obese individuals and the normal-weight controls in the derived cortisol parameters and in the baseline levels. For the specification of the response to the psychological stress condition (TSST) in both groups, the participants were categorized into non-responders and responders based on the criterion of a cortisol increase of at least $1.5 \mathrm{nmol} / \mathrm{L}$ [31].

Third, the $t$ test for independent samples in the questionnaires PASA and VAS was carried out to specify the differences in the appraisal of the stress condition between the obese adults and the normal-weight controls.

\section{Results}

\section{Sample Characteristics and Psychological Responses}

Table 1 presents a short description of the sociodemographic variables of the study participants. The obese group and the normal-weight control group were successfully matched with regard to the variables gender and age. Furthermore, there was no significant difference between the two groups in the influencing factors of cortisol such as contraceptives, regular sport activity, and healthy well-being. Additionally, the result of the subscale of chronic stress of the TICS showed no significant difference $\left(t_{(1,62)}=-1.837 ; p=0.07\right)$ between the obese individuals and the normal-weight controls.

All participants exhibited values higher than 0 in the VAS, which demonstrated perceived acute stress in the TSST without a significant difference between both groups $\left(t_{(1,62)}=-0.090\right.$; $p=0.93$ ). With regard to the appraisal of the stress condition (PASA), the obese adults and the normal-weight controls showed significant differences in the primary scales "challenge" $\left(t_{(1,62)}=2.242, p<0.05\right)$ and "self concept" $\left(t_{(1,62)}=2.203 ; p<0.05\right)$ as well as in the secondary scale "secondary appraisal" $\left(t_{(1,62)}=2.145 ; p<0.05\right)$ (Table 2$)$.

\section{Cortisol Stress Response}

There were significantly higher baseline cortisol levels in the normal-weight controls in contrast to the obese individuals (cortisol ${ }_{-15 \mathrm{~min}}: t_{(1,62)}=3.466 ; p<0.01$; cortisol $_{-1 \mathrm{~min}}$ : $\left.t_{(1,62)}=4.015 ; p<0.001\right)$. 
Herhaus and Petrowski: Cortisol Stress Reactivity to the Trier Social Stress Test in

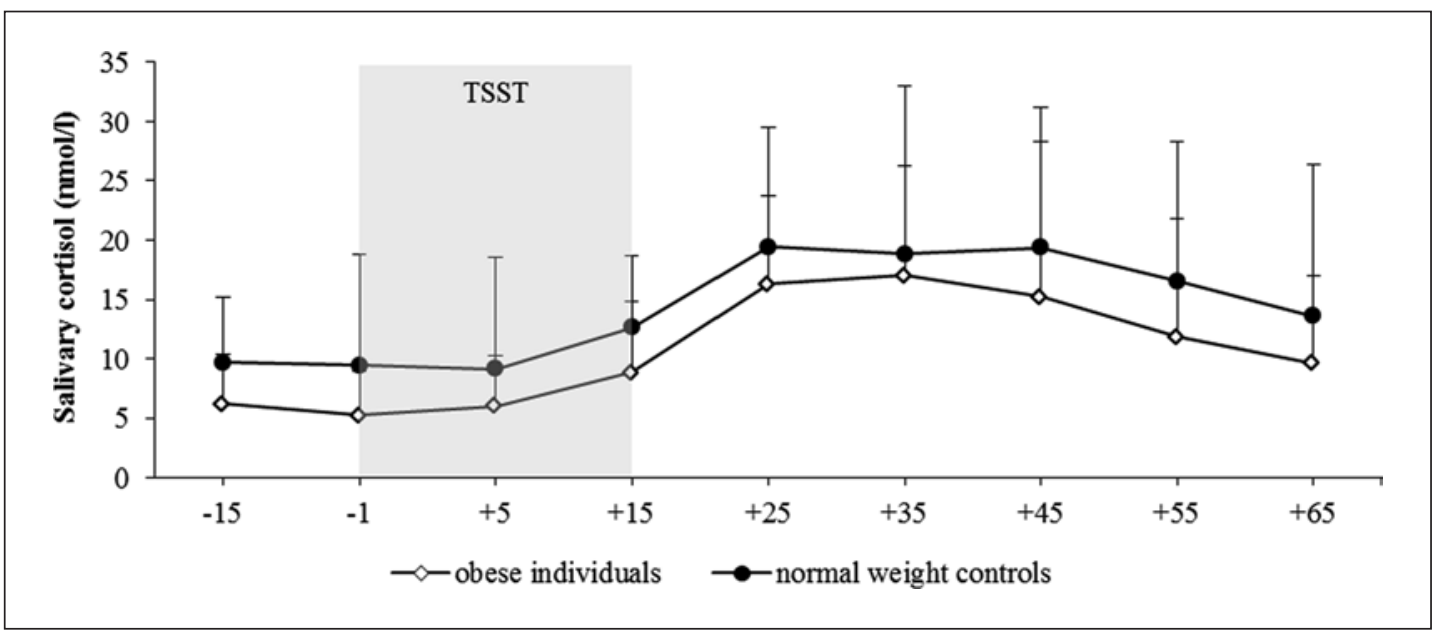

Fig. 2. Salivary cortisol concentration $(M \pm S D)$ during stress condition in obese individuals and normalweight controls. TSST, Trier Social Stress Test.

Table 2. Influence of stress condition in obese individuals and normal-weight controls on subjective appraisal and hormonal response

$\begin{array}{llll}\text { Obese individuals } & \text { Normal-weight } & t(1,62) & p \\ \text { M (SD) } & \text { controls M (SD) } & & \end{array}$

\begin{tabular}{lcrrr}
\hline $\begin{array}{l}\text { Subjective appraisal } \\
\text { PASA }\end{array}$ & & & & \\
$\quad$ Threat (1-6) & $3.55(.88)$ & $3.24(0.95)$ & -1.326 & 0.190 \\
Challenge (1-6) & $4.01(.82)$ & $4.43(0.66)$ & 2.242 & $0.029^{*}$ \\
Self concept (1-6) & $3.71(.95)$ & $4.20(0.83)$ & 2.203 & $0.031^{*}$ \\
Control expectancy (1-6) & $4.46(.99)$ & $4.71(0.86)$ & 1.068 & 0.290 \\
Primary appraisal (1-6) & $3.78(.78)$ & $3.84(0.69)$ & 0.311 & 0.757 \\
Secondary appraisal (1-6) & $4.09(.73)$ & $4.46(0.64)$ & 2.145 & $0.036^{*}$ \\
Stress index (-5 to +5) & $-0.31(1.08)$ & $-0.62(0.98)$ & -1.207 & 0.232 \\
VAS & $54.81(15.36)$ & $54.35(10.15)$ & -0.090 & 0.928 \\
\hline Hormonal response & & & & \\
Derived cortisol parameters & $797.41(617.14)$ & $1,027.95(518.90)$ & 2.865 & $0.006^{* *}$ \\
AUC & & $416.14(485.34)$ & -1.453 & 0.151 \\
AUC $_{\mathrm{I}}$ & $457.56(484.99)$ & $14.00(13.51)$ & -1.827 & 0.072 \\
$\quad$ peak-base & $14.47(14.40)$ & & \\
\hline
\end{tabular}

$\Delta=$ delta values; $\mathrm{AUC}_{\mathrm{G}}=$ area under the curve with respect to ground; $\mathrm{AUC}_{\mathrm{I}}=$ area under the curve with respect to increase; $\mathrm{M}=$ mean; PASA = primary appraisal secondary appraisal; $\mathrm{SD}=$ standard deviation; VAS = visual analogue scale. ${ }^{*} p \leq 0.05 ;{ }^{* *} p \leq 0.01 ; * * * 0.001$.

Both groups showed a TSST-induced reaction, with a $275 \%$ increase in the cortisol concentration (Fig. 2) and no significant difference in the responder rates (normal-weight controls $97 \%$, obese individuals $88 \% ; \chi^{2}=1.953, d f=1 ; p=0.16$ ).

ANCOVA results indicated a significant effect of time over the eight measurement points $\left(F_{(2.607,156.443)}=5.482 ; p<0.001 ; \eta^{2}=0.084\right)$. Furthermore, a significant main effect of group could be unveiled for cortisol with higher values in the normal-weight individuals $\left(F_{(1,60)}=\right.$ 
Herhaus and Petrowski: Cortisol Stress Reactivity to the Trier Social Stress Test in Obese Adults

8.918; $\left.p<0.01 ; \eta^{2}=0.129\right)$ and no significant interaction effect time $\times \operatorname{group}\left(F_{(2.607,156.443)}=\right.$ $\left.0.666 ; p=0.70 ; \eta^{2}=0.011\right)$. Any influence of oral contraceptive use $\left(F_{(2.281,66.151)}=0.870\right.$; $\left.p=0.436 ; \eta^{2}=0.029\right)$, smoking status $\left(F_{(2.607,156.443)}=0.403 ; p=0.723 ; \eta^{2}=0.007\right)$, and age $\left(F_{(2.607,156.443)}=0.250 ; p=0.835 ; \eta^{2}=0.004\right)$ on within-factor time could be excluded.

With regard to the $\mathrm{AUC}_{\mathrm{G}}$, a significant difference between both groups could be unveiled $\left(t_{(1,62)}=2.865 ; p<0.01\right)$. Concerning $\operatorname{AUC}_{\mathrm{I}}\left(t_{(1,62)}=-1.453 ; p=0.15\right)$ and $\Delta$ peak-base $\left(t_{(1,62)}=-1.827 ; p=0.07\right)$, there were no significant differences between the two groups.

\section{Discussion}

The present study investigated the hormonal stress reactivity to the TSST in obese adults and a matched normal-weight control group. The results indicate that obese individuals and normal-weight controls showed an increase in the cortisol concentration after the induction of the stress condition. Differences could be observed in the cortisol activity between the two groups, but not in the reactivity. The normal-weight controls showed significantly higher cortisol baseline levels, higher cortisol concentrations at the end of the recovery phase, and a significantly higher $\mathrm{AUC}_{\mathrm{G}}$ over the entire testing time.

Concerning studies using the established protocol of the TSST in obese individuals, the magnitude of the cortisol response of our study is comparable. The results of the studies by Benson et al. [21], Jayasinghe et al. [18], and Therrien et al. [19] indicated a magnitude of the cortisol response between 82 and 372\% increase to the TSST. Our study demonstrated a $275 \%$ increase in the cortisol concentration of both groups and a $327 \%$ increase in the obese individuals. In contrast to the present results, the studies by Lorig et al. [17] and Benson et al. [21] demonstrated a main effect of obesity in the cortisol response. However, Jayasinghe et al. [18], McInnis et al. [20], and Therrien et al. [19] indicated no significant difference in the cortisol response between obese and normal-weight women during the TSST which is in line with the present results.

The most common explanation for an altered cortisol metabolism in obesity is the role of the transformation-enzyme $11 \beta-\mathrm{HSD}_{1}$ which is expressed mostly in the liver and in adipose tissue [32]. Accordingly, increased adipose tissue also leads to an increased expression of $11 \beta-\mathrm{HSD}_{1}$ and thus has a strong influence on the HPA axis activity [33]. The enzyme does not only have the function of converting cortisone to cortisol but is also a competitor of enzyme $11 \beta-\mathrm{HSD}_{2}$ which converts cortisol to cortisone [34]. In spite of the cortisol metabolism-influencing transformation-enzyme $11 \beta-\mathrm{HSD}_{1}$, there is no clear evidence in the cortisol reactivity using the TSST. A possible explanation might be the unclear classification into obese and normal-weight adults with regard to the BMI [18]. Benson et al. [21] demonstrated higher cortisol reactivity in a BMI group of $38.2 \mathrm{~kg} / \mathrm{m}^{2}$ in contrast to the control group with an average BMI of $23.1 \mathrm{~kg} / \mathrm{m}^{2}$. Therefore, studies without the clear classification of obesity and normal-weight have demonstrated no main effect of obesity $[18,20]$. While this appears to be an attractive speculation, the study by Therrien et al. [19] and our investigation showed a main effect of obesity in the cortisol level in two clearly separated groups according to BMI, but not in the cortisol reactivity.

The present results also revealed significant differences in the cortisol activity between the obese individuals and the normal-weight controls. Champaneri et al. [35] showed an inverse relationship between obesity and the cortisol concentration over the entire day. Our results can replicate this observation but incorporate only a small period of time. Possible reasons for a lower cortisol activity are alterations in the reductase activity of $11 \beta$-HSD in the liver and adipose tissue [36] as well as the effect of long-term chronic stress on the HPA axis [37]. This lower cortisol activity of the obese individuals might influence the stress-related cortisol reactivity. 
Beside the transformation-enzyme $11 \beta-\mathrm{HSD}_{1}$ leading to a higher cortisol output, longterm chronic stress and low cortisol activity level might result in a blunted reactivity in obesity. The chronic stress response network model of Dallman et al. [38] and Dallman [39] describes the association between chronic stress, stress reactivity and BMI. Thereby, high chronic stress is regulated by more food; this will result in a greater amount of fat, and longterm blunted stress reactivity will be developed [40]. This theoretical approach can be supported by the higher values in the TICS in the obese individuals of the present results.

In view of the cognitive stress appraisal with significantly higher values in the scales "challenge" and "self-concept" of the normal-weight controls, it must be considered that there is an association between psychosocial appraisal factors and cortisol reactivity [16, 41]. A study by Juster et al. [42] in healthy participants demonstrated that increased anticipatory stress using the PASA predicted higher cortisol stress reactivity. On the one hand, it could be speculated that in the present study the differences in the stress appraisal explain the lack of differences in the cortisol reactivity. On the other hand, the results are contradictory because higher challenge suggests higher reactivity, and higher self-concept indicates lower reactivity [43].

Overall, the present results suggest a dysregulated activity of the HPA axis in obese individuals with regard to the cortisol activity. One strength of the present study was that the two investigated groups were clearly separated according to ICD-10 in normal-weight controls $\left(\mathrm{BMI} \leq 25 \mathrm{~kg} / \mathrm{m}^{2}\right)$ and obese individuals (BMI $\geq 30 \mathrm{~kg} / \mathrm{m}^{2}$ ) with equally distributed numbers of males and females. Furthermore, aspects of age and gender did not represent confounding factors in the evaluation of the HPA axis in both groups. Consequently, the focus was on the effect of increased general fat tissue onto the altered metabolism of the HPA axis in obesity.

Further strengths of this study are the use of a standardized and reliable psychosocial stress test (TSST) as well as the methodological procedures with the control of confounders in the cortisol assessment (e.g. menstrual cycle or circadian rhythm of the cortisol, regular sport activity) and strict exclusion criteria (e.g. any acute and/or chronic medical illness, any mental disorders, any medication or substance intake). Limiting factors are the missing consideration of the WHR with regard to the determination of abdominal and visceral obesity.

In conclusion, the induction of psychosocial stress showed differences in the cortisol patterns between obese individuals and normal-weight controls. Furthermore, the present data suggest lower cortisol activity in obesity, which indicates alterations in the HPA axis in this risk factor/medical condition.

\section{Funding and Support}

This study was funded by the DFG project "Comparison of the chewing behavior of patients with obesity and healthy controls under resting and stress condition” (Project-number: 276734837).

\section{Disclosure Statement}

The authors have no conflict of interest to disclose. 
Herhaus and Petrowski: Cortisol Stress Reactivity to the Trier Social Stress Test in Obese Adults

\section{References}

1 WHO. Obesity and Overweight 2016 [cited 2017 Jan 27]; Available from: http://www.who.int/mediacentre/ factsheets/fs311/en/

2 Ogden CL, Carroll MD, Fryar CD, Flegal KM. Prevalence of Obesity among Adults and Youth: United States, 2011-2014 2015; Available from: https://www.cdc.gov/nchs/data/databriefs/db219.pdf

3 Flegal KM, Graubard BI, Williamson DF, Gail MH. Cause-specific excess deaths associated with underweight, overweight, and obesity. JAMA. 2007 Nov;298(17):2028-37.

4 Abraham SB, Rubino D, Sinaii N, Ramsey S, Nieman LK. Cortisol, obesity, and the metabolic syndrome: a crosssectional study of obese subjects and review of the literature. Obesity (Silver Spring). 2013 Jan;21(1):E10517.

5 Scott KA, Melhorn SJ, Sakai RR. Effects of Chronic Social Stress on Obesity. Curr Obes Rep. 2012 Mar;1(1): $16-25$.

6 Tryon MS, DeCant R, Laugero KD. Having your cake and eating it too: a habit of comfort food may link chronic social stress exposure and acute stress-induced cortisol hyporesponsiveness. Physiol Behav. 2013 Apr;114115:32-7.

7 McEwen BS. Central effects of stress hormones in health and disease: understanding the protective and damaging effects of stress and stress mediators. Eur J Pharmacol. 2008 Apr;583(2-3):174-85.

8 Pedersen SB, Jønler M, Richelsen B. Characterization of regional and gender differences in glucocorticoid receptors and lipoprotein lipase activity in human adipose tissue. J Clin Endocrinol Metab. 1994 Jun; 78(6): 1354-9.

9 Rosmond R, Dallman MF, Björntorp P. Stress-related cortisol secretion in men: relationships with abdominal obesity and endocrine, metabolic and hemodynamic abnormalities. J Clin Endocrinol Metab. 1998 Jun;83(6): 1853-9.

10 Incollingo Rodriguez AC, Epel ES, White ML, Standen EC, Seckl JR, Tomiyama AJ. Hypothalamic-pituitaryadrenal axis dysregulation and cortisol activity in obesity: A systematic review. Psychoneuroendocrinology. 2015 Dec;62:301-18.

11 Epel ES, McEwen B, Seeman T, Matthews K, Castellazzo G, Brownell KD, et al. Stress and body shape: stressinduced cortisol secretion is consistently greater among women with central fat. Psychosom Med. 2000 Sep-0ct;62(5):623-32.

12 Duclos M, Marquez Pereira P, Barat P, Gatta B, Roger P. Increased cortisol bioavailability, abdominal obesity, and the metabolic syndrome in obese women. Obes Res. 2005 Jul;13(7):1157-66.

13 Vicennati V, Pasquali R. Abnormalities of the hypothalamic-pituitary-adrenal axis in nondepressed women with abdominal obesity and relations with insulin resistance: evidence for a central and a peripheral alteration. J Clin Endocrinol Metab. 2000 Nov;85(11):4093-8.

14 Mårin P, Darin N, Amemiya T, Andersson B, Jern S, Björntorp P. Cortisol secretion in relation to body fat distribution in obese premenopausal women. Metabolism. 1992 Aug;41(8):882-6.

15 Kirschbaum C, Wüst S, Faig HG, Hellhammer DH. Heritability of cortisol responses to human corticotropinreleasing hormone, ergometry, and psychological stress in humans. J Clin Endocrinol Metab. 1992 Dec;75(6): 1526-30.

16 Dickerson SS, Kemeny ME. Acute stressors and cortisol responses: a theoretical integration and synthesis of laboratory research. Psychol Bull. 2004 May;130(3):355-91.

17 Lorig F, Kießl GR, Laessle RG. Stress-related cortisol response and laboratory eating behavior in obese women. Eat Weight Disord. 2016 Jun;21(2):237-43.

18 Jayasinghe SU, Torres SJ, Nowson CA, Tilbrook AJ, Turner AI. Physiological responses to psychological stress: importance of adiposity in men aged 50-70 years. Endocr Connect. 2014 Sep;3(3):110-9.

19 Therrien F, Drapeau V, Lalonde J, Lupien SJ, Beaulieu S, Doré J, et al. Cortisol response to the Trier Social Stress Test in obese and reduced obese individuals. Biol Psychol. 2010 May;84(2):325-9.

20 McInnis CM, Thoma MV, Gianferante D, Hanlin L, Chen X, Breines JG, et al. Measures of adiposity predict interleukin-6 responses to repeated psychosocial stress. Brain Behav Immun. 2014 Nov;42:33-40.

21 Benson S, Arck PC, Tan S, Mann K, Hahn S, Janssen OE, et al. Effects of obesity on neuroendocrine, cardiovascular, and immune cell responses to acute psychosocial stress in premenopausal women. Psychoneuroendocrinology. 2009 Feb;34(2):181-9.

22 Wittchen HU, Zaudig M, Fydrich T. Strukturiertes Klinisches Interview für DSM-IV. Göttingen: Hogrefe; 1997.

23 APA. Diagnostic and Statistical Manual of Mental disorders. DSM-IV-TR. 4th ed. Washington (DC): American Psychiatric Association; 2000.

24 Dressendörfer RA, Kirschbaum C, Rohde W, Stahl F, Strasburger CJ. Synthesis of a cortisol-biotin conjugate and evaluation as a tracer in an immunoassay for salivary cortisol measurement. J Steroid Biochem Mol Biol. 1992 Dec;43(7):683-92.

25 Kirschbaum C, Pirke KM, Hellhammer DH. The 'Trier Social Stress Test' - a tool for investigating psychobiological stress responses in a laboratory setting. Neuropsychobiology. 1993;28(1-2):76-81.

26 Kudielka BM, Hellhammer H, Kirschbaum C. Ten years of research with the trier social stress test (TSST) Revisited. In: Harmon-Jones E, Winkielman P, editors. Social neuroscience: Integrating biological and psychological explanations of social behavior. New York: Guilford Press; 2007. pp. 56-83.

27 Schulz P, Schlotz W, Becker P. Trierer Inventar zum chronischen Stress (TICS). Göttingen: Hogrefe; 2004. 
Herhaus and Petrowski: Cortisol Stress Reactivity to the Trier Social Stress Test in Obese Adults

28 Gaab J. PASA - Primary appraisal secondary appraisal. Verhaltenstherapie. 2009;19(2):114-5.

29 Lesage FX, Berjot S, Deschamps F. Clinical stress assessment using a visual analogue scale. Occup Med (Lond). 2012 Dec;62(8):600-5.

30 Fekedulegn DB, Andrew ME, Burchfiel CM, Violanti JM, Hartley TA, Charles LE, et al. Area under the curve and other summary indicators of repeated waking cortisol measurements. Psychosom Med. 2007 Sep-0ct;69(7): 651-9.

31 Miller R, Plessow F, Kirschbaum C, Stalder T. Classification criteria for distinguishing cortisol responders from nonresponders to psychosocial stress: evaluation of salivary cortisol pulse detection in panel designs. Psychosom Med. 2013 Nov-Dec;75(9):832-40.

32 Tomlinson JW, Walker EA, Bujalska IJ, Draper N, Lavery GG, Cooper MS, et al. 11ß-hydroxysteroid dehydrogenase type 1: a tissue-specific regulator of glucocorticoid response. Endocr Rev. 2004 Oct;25(5):831-66.

33 Sandeep TC, Andrew R, Homer NZ, Andrews RC, Smith K, Walker BR. Increased in vivo regeneration of cortisol in adipose tissue in human obesity and effects of the 11 beta-hydroxysteroid dehydrogenase type 1 inhibitor carbenoxolone. Diabetes. 2005 Mar;54(3):872-9.

34 Seckl JR. 11ß-hydroxysteroid dehydrogenases: changing glucocorticoid action. Curr Opin Pharmacol. 2004 Dec;4(6):597-602.

35 Champaneri S, Xu X, Carnethon MR, Bertoni AG, Seeman T, DeSantis AS, et al. Diurnal salivary cortisol is associated with body mass index and waist circumference: the Multiethnic Study of Atherosclerosis. Obesity (Silver Spring). 2013 Jan;21(1):E56-63.

36 Rask E, Olsson T, Söderberg S, Andrew R, Livingstone DE, Johnson O, et al. Tissue-specific dysregulation of cortisol metabolism in human obesity. J Clin Endocrinol Metab. 2001 Mar;86(3):1418-21.

37 Tsigos C, Kyrou I, Kassi E, Chrousos G. Stress, Endocrine physiology and pathophysiology. Endotext; 2016. pp. $1-44$.

38 Dallman MF, Akana SF, Strack AM, Scribner KS, Pecoraro N, La Fleur SE, et al. Chronic stress-induced effects of corticosterone on brain: direct and indirect. Ann N Y Acad Sci. 2004 Jun;1018(1):141-50.

39 Dallman MF. Stress-induced obesity and the emotional nervous system. Trends Endocrinol Metab. 2010 Mar; 21(3):159-65.

40 Tomiyama AJ, Dallman MF, Epel ES. Comfort food is comforting to those most stressed: evidence of the chronic stress response network in high stress women. Psychoneuroendocrinology. 2011 Nov;36(10):1513-9.

41 Denson TF, Spanovic M, Miller N. Cognitive appraisals and emotions predict cortisol and immune responses: a meta-analysis of acute laboratory social stressors and emotion inductions. Psychol Bull. 2009 Nov; 135(6): 823-53.

42 Juster RP, Perna A, Marin MF, Sindi S, Lupien SJ. Timing is everything: anticipatory stress dynamics among cortisol and blood pressure reactivity and recovery in healthy adults. Stress. 2012 Nov;15(6):569-77.

43 Gaab J, Rohleder N, Nater UM, Ehlert U. Psychological determinants of the cortisol stress response: the role of anticipatory cognitive appraisal. Psychoneuroendocrinology. 2005 Jul;30(6):599-610. 